\title{
Erratum to: Optimization of method to quantify soil organic matter dynamics and carbon sequestration potential in volcanic ash soils
}

\author{
Susan E. Crow • Mataia Reeves • \\ Olivia S. Schubert · Carlos A. Sierra
}

Received: 1 February 2014/ Accepted: 6 November 2014/Published online: 21 December 2015

(C) Springer International Publishing Switzerland 2015

\section{Erratum to: Biogeochemistry (2015) 123:27-47 DOI 10.1007/s10533-014-0051-6}

During finalization of the revised manuscript that included an improved radiocarbon modeling approach, an error occurred in a written form of the model description. Specifically, pool "3" was substituted for pool " 4 " in text describing the model structure and the error was then propagated through the data reported in Table 4, the conceptual diagram in Fig. 7, and accompanying results and discussion. The model parameterization and optimization was correct, but the reporting of the proportion of carbon transfer from pool 1 to pool 4 was erroneously described and interpreted as being from pool 1 to pool 3 .

The online version of the original article can be found under doi:10.1007/s10533-014-0051-6.

S. E. Crow $(\bowtie) \cdot$ M. Reeves · O. S. Schubert

Natural Resources and Environmental Management Department (NREM Department), University of Hawaii Manoa, 1910 East-West Road, Sherman Lab 101, Honolulu, HI 96822, USA

e-mail: crows@hawaii.edu

\section{A. Sierra}

Max Planck Institute for Biogeochemistry, Hans Knöll Straße 10, 07745 Jena, Germany 